Article

\title{
Influence of Nitrogen Partial Pressure on Microstructure and Tribological Properties of Mo-Cu-V-N Composite Coatings with High $\mathrm{Cu}$ Content
}

\author{
Haijuan Mei ${ }^{1}$, Rui Wang ${ }^{1,2}$, Xing Zhong ${ }^{1}$, Wei Dai ${ }^{1, *}$ and Qimin Wang ${ }^{1, *}$ \\ 1 School of Electromechanical Engineering, Guangdong University of Technology, Guangzhou 510006, China; \\ haijuanmei@126.com (H.M.); wanrui@guat.edu.cn (R.W.); zhongxing921@126.com (X.Z.) \\ 2 School of Mechanical Engineering, Guilin University of Aerospace Technology, Guilin 541004, China \\ * Correspondence: popdw@126.com (W.D.); qmwang@gdut.edu.cn (Q.W.)
}

Received: 19 November 2017; Accepted: 27 December 2017; Published: 4 January 2018

\begin{abstract}
In this study, Mo-Cu-V-N composite coatings with high $\mathrm{Cu}$ content of $\sim 18$ at.\% were deposited on 316L stainless steel and YT14 cemented carbide substrates by high power impulse magnetron sputtering in $\mathrm{Ar}-\mathrm{N}_{2}$ gas mixtures. The influence of $\mathrm{N}_{2}$ partial pressure was investigated with respect to the microstructure and tribological properties of the coatings. The results indicated that the Mo-Cu-V-N composite coatings exhibited FCC B1-MoN phase with a strong (200) preferred orientation, and $\mathrm{Cu}$ phase was found to exist as metallic species. As the $\mathrm{N}_{2}$ partial pressure increased from 0.11 to $0.35 \mathrm{~Pa}$, the peak intensity of (200) plane decreased gradually and simultaneous peak broadening was observed, which was typical for grain refinement. With increasing the $\mathrm{N}_{2}$ partial pressure, the columnar microstructure became much coarser, which led to the decrease of residual stress and hardness. The Mo-Cu-V-N composite coatings with high $\mathrm{Cu}$ content exhibited a relatively low wear rate of $10^{-8} \mathrm{~mm}^{3} / \mathrm{N} \cdot \mathrm{m}$ at $25^{\circ} \mathrm{C}$, which was believed to be attributed to the mixed lubricious oxides of $\mathrm{MoO}_{2}, \mathrm{CuO}$ and $\mathrm{V}_{2} \mathrm{O}_{5}$ formed during tribo-oxidation, which cannot be formed in the coatings with low $\mathrm{Cu}$ content. When the wear temperature was increased up to $400{ }^{\circ} \mathrm{C}$, the wear rate increased sharply up to $10^{-6} \mathrm{~mm}^{3} / \mathrm{N} \cdot \mathrm{m}$ despite the formation of lubricious oxides of $\mathrm{MoO}_{3} / \mathrm{CuMoO}_{4}$ and $\mathrm{V}_{2} \mathrm{O}_{5}$. This could be due to the loss of nitrogen and pronounced oxidation at high temperatures, which led the wear mechanism to be transformed from mild oxidation wear to severe oxidation wear.
\end{abstract}

Keywords: Mo-Cu-V-N; HIPIMS; $\mathrm{N}_{2}$ partial pressure; microstructure; tribological properties

\section{Introduction}

In the last decade, solid lubricants have been developed to achieve favorable abrasion resistance and good lubricating capability in various tribological applications [1-3]. However, the tribological effectiveness of solid lubricants often begins to fail due to the thermal degradation or oxidation at elevated temperatures [4-6]. In recent years, some lubricious materials at elevated temperatures have been investigated by using oxide materials. These lubricious oxides are often referred to as Magnéli phases, which usually shows easy crystallographic shear planes, good oxidation stability and excellent tribological properties [7]. Among these, molybdenum and vanadium nitrides have been achieved to reduce the friction coefficient at high temperatures. The self-lubricating effect is based on the formation of lubricious oxides of $\mathrm{MoO}_{3}$ [8-10] and $\mathrm{V}_{2} \mathrm{O}_{5}$ [11-13]. In addition, some soft metals also possess lubrication properties due to their low shear strength and high plasticity. Recently, soft metals like $\mathrm{Cu}$ have been added into Mo-N coatings to form nanocomposite coatings to achieve better tribological performance $[14,15]$. Thus, multi-functional self-lubricating coatings can be obtained by the addition of these alloying elements. 
Up to now, few studies have reported on the self-lubricating coatings deposited by high power impulse magnetron sputtering (HIPIMS). The high plasma density and large fraction of ionized species created in a high-power impulse magnetron sputtering discharge allows for a better control of the process parameters [16]. It has been well documented that the microstructure and mechanical properties of magnetron sputtered metal nitride coatings strongly depend on the nitrogen flow rate [17-19]. While the effect of nitrogen partial pressure on the microstructure and mechanical properties of $\mathrm{Mo}-\mathrm{Cu}-\mathrm{V}-\mathrm{N}$ composite coatings has been investigated in our previous work [20], the formation of $\mathrm{CuMoO}_{4}$ lubricious oxides has not been found during the tribological test at room temperature, which would be due to the low content of $\mathrm{Cu}$ in the Mo-Cu-V-N composite coatings. It has been reported that the average friction coefficient of the Mo-Cu-N coatings decreased from 0.40 to 0.21 with increasing $\mathrm{Cu}$ content up to 11 at.\% due to the formation of lubricious oxides of $\mathrm{CuMoO}_{4}$, which possesses better self-lubricating behavior than $\mathrm{MoO}_{3}$ due to difference in ionic potential of $\mathrm{MoO}_{3}$ and $\mathrm{CuO}$ [21]. It also has been reported that double oxides from binary alloy systems can effectively reduce the coefficient of friction [22]. It is essential to reduce the friction coefficient and improve the wear resistance of the self-lubricating coatings for industrial applications. In addition, studies on the tribological properties of Mo-Cu-V-N coatings at elevated temperatures are rarely reported in the literature.

Therefore, the aim of this work is to prepare the Mo-Cu-V-N composite coatings with high $\mathrm{Cu}$ content to further investigate the influence of $\mathrm{N}_{2}$ partial pressure on the microstructure, residual stress and tribological properties, and to find out the wear mechanism of the self-lubricating coatings at elevated temperatures up to $400{ }^{\circ} \mathrm{C}$.

\section{Experimental}

\subsection{Coating Deposition}

Mo-Cu-V-N composite coatings were deposited on the polished AISI 316L stainless steel and YT14 (WC-14\%TiC-8\%Co) cemented carbide substrates by high power impulse magnetron sputtering unit (ProChina Limited, Beijing, China) using a rectangular spliced target $(69 \mathrm{~mm} \times 443 \mathrm{~mm})$. The Mo-Cu-V spliced target with three kinds of metal targets of Mo (99.99\%), $\mathrm{Cu}(99.99 \%)$ and $\mathrm{V}(99.99 \%)$ was installed on the side walls of the chamber. Similar schematic diagrams of the Mo- $\mathrm{Cu}-\mathrm{V}$ spliced target had been used in our previous studies [20]. The only difference in this work was the location of the rotational substrate holder, which was located in the middle center of the spliced target to deposit the coatings with high $\mathrm{Cu}$ content. The stainless steel was selected as a substrate for testing of residual stress, while the cemented carbide substrates were used for the test of microstructure and mechanical properties of the Mo-Cu-V-N coatings. All the substrates were ultrasonically cleaned first in acetone and then in alcohol for $10 \mathrm{~min}$, respectively. The substrates were then blown dry with compressed air and mounted on the substrate holder, which was rotated at a speed of $3 \mathrm{rpm}$. Prior to the coating deposition, the chamber was evacuated to a base pressure of $5.0 \times 10^{-3} \mathrm{~Pa}$, and the substrate temperature was then heated to $100^{\circ} \mathrm{C}$. To remove surface contaminates, the substrates were etched by Ar plasma with a $\mathrm{DC}$ bias of $-1000 \mathrm{~V}$ at a gas pressure of $1.8 \mathrm{~Pa}$ for $15 \mathrm{~min}$. During the deposition, the Mo-Cu-V-N composite coatings were deposited by HIPIMS at a working pressure of $0.7 \mathrm{~Pa}$ with the $\mathrm{N}_{2}$ partial pressure increased from 0.11 to $0.35 \mathrm{~Pa}$. The coating deposition time was maintained at $180 \mathrm{~min}$ to obtain the coatings with thickness ranging from 2.1 to $2.4 \mu \mathrm{m}$. The detail deposition conditions is summarized in Table 1. 
Table 1. The detail parameters of the experiment.

\begin{tabular}{ccc}
\hline Process & Parameters & Values \\
\hline \multirow{3}{*}{ Ar glow discharge } & Bias voltage $(\mathrm{V})$ & -1000 \\
& Ar flow rate $(\mathrm{sccm})$ & 300 \\
& Time (min) & 15 \\
\hline \multirow{3}{*}{ Ion etching } & Bias voltage $(\mathrm{V})$ & 800 \\
& Cathode current (A) & 100 \\
& Time (min) & 5 \\
\hline & Working pressure $(\mathrm{Pa})$ & 0.7 \\
& $\mathrm{~N}_{2}$ partial pressure $(\mathrm{Pa})$ & -100 \\
& Bias voltage $(\mathrm{V})$ & 1.0 \\
& Sputtering power (kW) & 150 \\
& Pulse width (us) & 400 \\
& Frequency (Hz) & $6 \%$ \\
& Duty cycle & 180 \\
\hline
\end{tabular}

\subsection{Coating Characterization}

The morphologies and chemical composition of the coatings were examined using a scanning electron microscope (SEM, FEI Nano430, Amsterdam, The Netherlands) equipped with an energy-dispersive X-ray spectrometer (EDS). The phase structure of the as-deposited coatings was characterized on an X-ray diffraction (XRD, Bruker D8 Advance, Bruker AXS, Karlsruhe, Germany) machine in the $\theta / 2 \theta$ geometry using $\mathrm{Cu} \mathrm{K} \alpha$ radiation $(40 \mathrm{kV}$ and $40 \mathrm{~mA})$. The chemical structure was investigated using X-ray photoelectron spectrometer (XPS, ESCALAB 250xi, Thermo Fisher Scientific, Waltham, MA, USA), and an Al K $\alpha$ X-ray source (13 kV and $15 \mathrm{~mA})$ was used. The scanning step for the full spectrum and individual spectrum was set at 1 and $0.1 \mathrm{eV}$, respectively. The XPS spectra were obtained after removing the surface contamination layer of the sample by in situ sputtering with $\mathrm{Ar}^{+}$ ions $(3 \mathrm{kV})$ for $120 \mathrm{~s}$, and were calibrated by carbon peak C1s at $284.6 \mathrm{eV}$.

The residual stress was measured by a Film Stress Tester (FST-1000, Supro Instruments, Shenzhen, China) according to the substrate curvature method based on Stoney's equation [23]. The coating hardness $(H)$ and elastic modulus $(E)$ were measured by nanoindenter (NHT2, CSM, Peseux, Switzerland) with a Berkovich diamond indenter. The maximum applied load was $10 \mathrm{mN}$, and the indentation depth was kept below $10 \%$ of the coating thickness. The tribological properties were investigated by using a high-temperature ball-on-disc tribometer (THT, CSM) in air at $25^{\circ} \mathrm{C}$ and $400^{\circ} \mathrm{C}$. $\mathrm{Al}_{2} \mathrm{O}_{3}$ ball with a 6-mm diameter was used as the counterpart. The sliding tests were conducted with a rotational speed of $400 \mathrm{r} / \mathrm{min}$ under a load of $5 \mathrm{~N}$ and a fixed period of 5000 rotating cycles. To measure the wear loss, the three-dimensional morphologies and two-dimensional (2D) cross-sectional profile of the wear tracks were obtained using a white light interferometer (Contour GT-X3, Bruker, Tucson, AZ, USA). The wear rates were calculated as the worn volume per normal load and the sliding distance.

\section{Results and Discussion}

\subsection{Microstructure and Mechanical Properties}

The chemical composition of Mo-Cu-V-N composite coatings deposited at various $\mathrm{N}_{2}$ partial pressures are shown in Figure 1. As the $\mathrm{N}_{2}$ partial pressure increased from 0.11 to $0.35 \mathrm{~Pa}$, the Mo content decreased from 39.4 at. $\%$ to 29.5 at. $\%$. At higher $\mathrm{N}_{2}$ partial pressure, the $\mathrm{N}_{2}{ }^{+} / \mathrm{Ar}^{+}$ratio increased and hence the sputtering yield of Mo atoms were reduced. As expected, the $\mathrm{N}$ content increased from 40.9 at. $\%$ to 50.5 at.\%. Meanwhile, small changes were found in both the $\mathrm{Cu}$ content and $\mathrm{V}$ content, which were in the range of 17.3 at. $\%$ to 19.3 at. $\%$ and 1.7 at. $\%$ to 2.5 at. $\%$, respectively. While the $\mathrm{Cu}$ content in the range of 9.2 at.\% to 11.4 at.\% was achieved in the $\mathrm{Mo}-\mathrm{Cu}-\mathrm{V}-\mathrm{N}$ coatings with low $\mathrm{Cu}$ content [20]. The high content of $\mathrm{Cu}$ and low content of $\mathrm{V}$ in the $\mathrm{Mo}-\mathrm{Cu}-\mathrm{V}-\mathrm{N}$ composite coatings deposited by HIPIMS could be explained by the different sputtering yields [24]. 


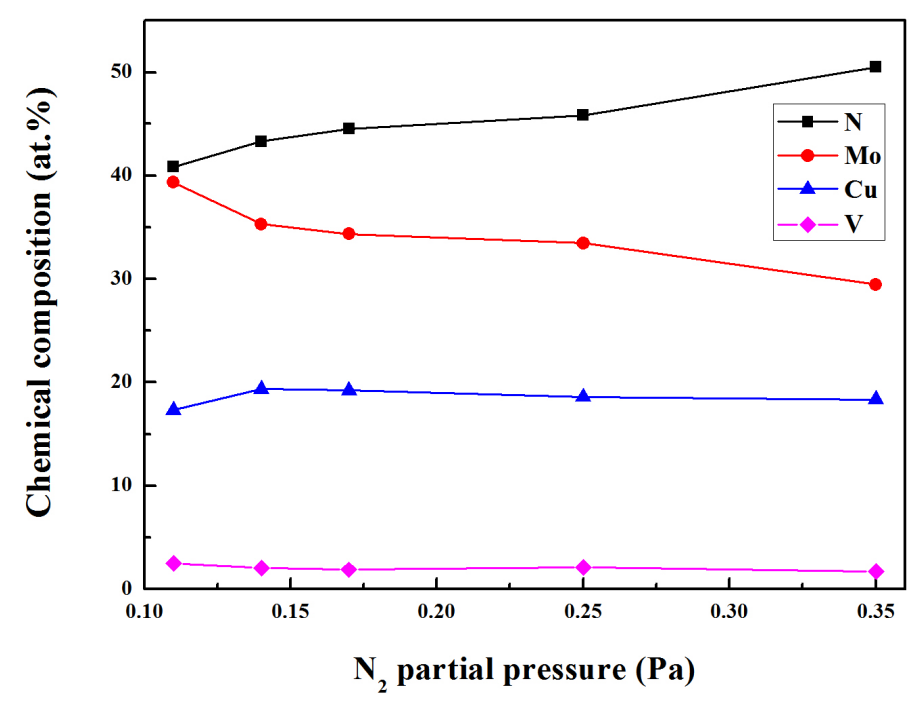

Figure 1. Chemical composition of $\mathrm{Mo}-\mathrm{Cu}-\mathrm{V}-\mathrm{N}$ composite coatings.

Figure 2a shows the XRD patterns of Mo-Cu-V-N composite coatings deposited at different $\mathrm{N}_{2}$ partial pressures. For all the coatings, three diffraction peaks at about $37.6^{\circ}, 42.9^{\circ}$ and $62.5^{\circ}$ were corresponding to (111), (200) and (220) crystal planes of face-centered-cubic Mo-N phase, respectively. Meanwhile, the Mo-Cu-V-N composite coatings revealed (200) diffraction peak of face-centered-cubic structure at about $51.3^{\circ}$, which corresponded to the FCC Cu phase. While no diffraction peaks of vanadium nitride phase were observed in the $\mathrm{Mo}-\mathrm{Cu}-\mathrm{V}-\mathrm{N}$ composite coatings, which could be due to the low content of $\mathrm{V}$ in the coatings. At the $\mathrm{N}_{2}$ partial pressure of $0.11 \mathrm{~Pa}$, the peak intensity of (200) plane was much higher than that of the other FCC peaks, indicating a high preferred orientation of the (200) grain. While the Mo-Cu-V-N composite coatings with $\mathrm{Cu}$ content below $~ 11$ at.\% exhibited FCC B1-MoN phase with a (111) preferred orientation [20]. Pelleg et al. [25] had reported that (111) orientation with the lowest strain energy might be expected when the strain energy was significant, and (200) orientation with the lowest surface energy may be observed when the surface energy was ultimately dominant. Thus, with the increase of the $\mathrm{Cu}$ content, the preferred orientation of $\mathrm{Mo}-\mathrm{Cu}-\mathrm{V}-\mathrm{N}$ coatings changed from (111) to (200) due to the increase of surface energy and the decrease of strain energy. However, with the increase of $\mathrm{N}_{2}$ partial pressure, the peak intensity of (200) plane decreased gradually with simultaneous peak broadening being observed, which was typical for the grain refinement. Similar results had been reported by Kim et al.; the peak intensity decreased with increase in nitrogen flow rate [15]. When the $\mathrm{N}_{2}$ flow rate increased, $\mathrm{N}$ provided reaction sites, which in turn increased nucleation sites, and then reduced the grain growth. In addition, the XRD peak positions gradually shifted toward lower diffraction angles with the increase of $\mathrm{N}_{2}$ partial pressure, indicating an increase in lattice parameters of the coatings. To analyze the peak shift quantitatively, lattice parameters of the Mo-N phase were calculated from the (200) peaks, as shown in Figure $2 \mathrm{~b}$. As the $\mathrm{N}_{2}$ partial pressure increased from 0.11 to $0.35 \mathrm{~Pa}$, the lattice parameters increased from 4.21 to $4.28 \AA$, which could be explained by the fact that the excess nitrogen atoms occupied interstitial positions of Mo-Cu-V-N coatings. According to Ref. [26], two FCC phases exist in the Mo-N system: $\gamma-\mathrm{Mo}_{2} \mathrm{~N}$ with lattice parameters of 4.16-4.19 $\AA$ and B1-MoN with lattice parameters of 4.20-4.27 $\AA$. Therefore, the FCC Mo-N phase would correspond to the FCC B1-MoN phase. While for the Mo-Cu-V-N coatings with low $\mathrm{Cu}$ content [20], the phase structure was found to change from $\mathrm{B} 1-\mathrm{MoN}$ to hex $\delta-\mathrm{MoN}$ phase with increasing the $\mathrm{N}_{2}$ partial pressure, which would be due to the higher nitrogen content in the coatings. 

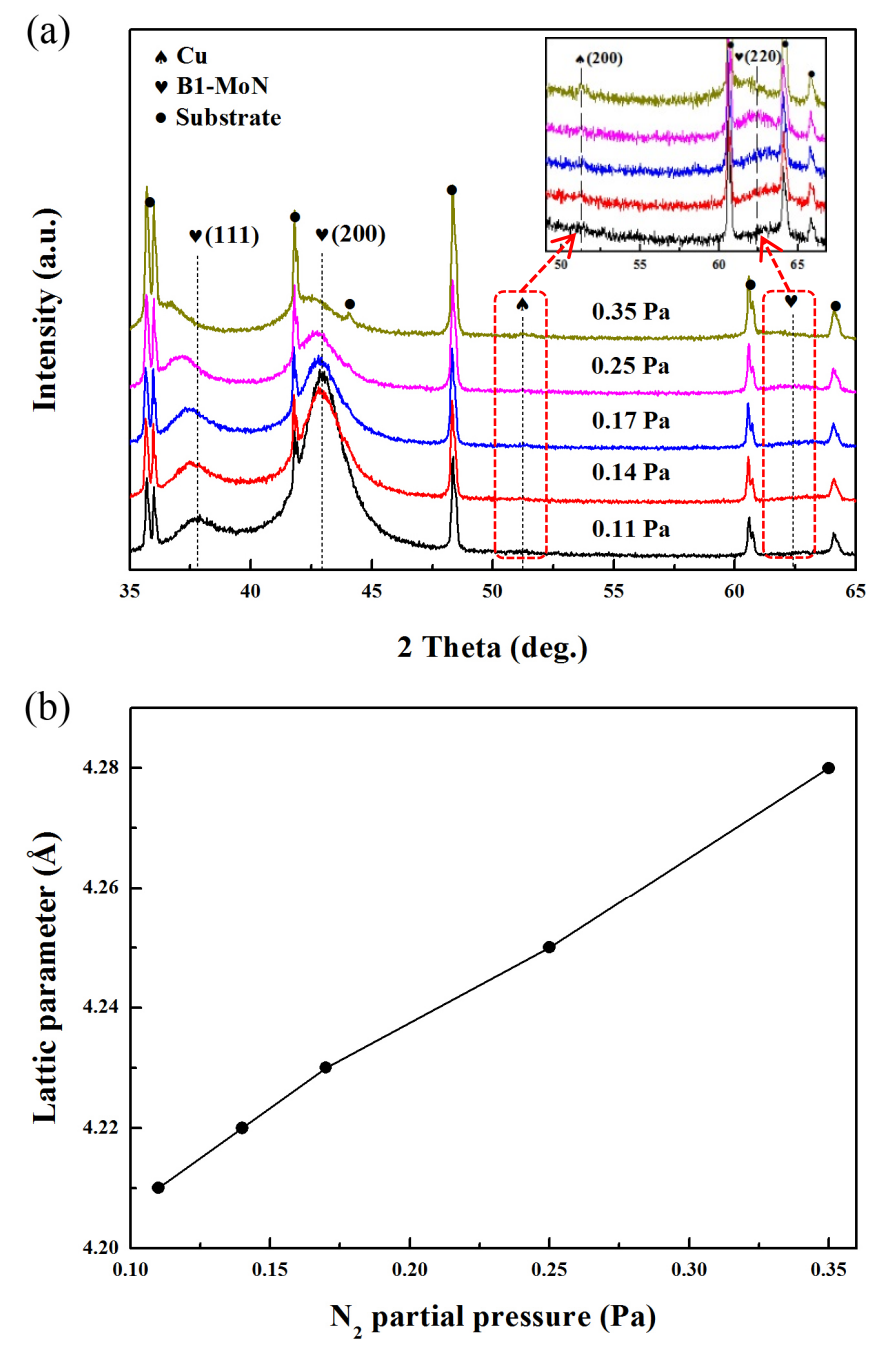

Figure 2. (a) X-ray diffraction patterns and (b) lattice parameters of $\mathrm{Mo}-\mathrm{Cu}-\mathrm{V}-\mathrm{N}$ coatings as a function of $\mathrm{N}_{2}$ partial pressure.

In order to obtain insight into the chemical bonding states, the Mo-Cu-V-N composite coating deposited at the $\mathrm{N}_{2}$ partial pressure of $0.11 \mathrm{~Pa}$ was investigated by using XPS. The $\mathrm{C}$ 1s peak at $284.6 \mathrm{eV}$ had been used as a reference to calibrate the XPS spectra. As shown in Figure 3a, the fitted Mo $3 \mathrm{~d}$ spectrum centered at $227.7 \mathrm{eV}$ and $230.8 \mathrm{eV}$ were recognized as $\mathrm{MoN}\left(3 \mathrm{~d}_{5 / 2}\right)$ and $\mathrm{MoN}\left(3 \mathrm{~d}_{3 / 2}\right)$, respectively. In addition, the peaks with a high binding energy of $228.8 \mathrm{eV}$ and $232.0 \mathrm{eV}$ were also found in the Mo $3 \mathrm{~d}$ spectrum, which corresponded to $\mathrm{MoO}_{2}\left(3 \mathrm{~d}_{5 / 2}\right)$ and $\mathrm{MoO}_{2}\left(3 \mathrm{~d}_{3 / 2}\right)$, respectively [27]. It indicated that the surface of Mo-Cu-V-N composite coating had been oxidized slightly, and most of the Mo atoms were involved in nitride bonding. Similar to the XPS analysis of as-deposited $\mathrm{MoN}_{\mathrm{x}}$ coatings, we found that the surface of $\mathrm{MoN}_{\mathrm{x}}$ coating deposited at low $\mathrm{N}_{2}$ flow rate had already been oxidized before the ball on disc test [28]. In Figure $3 \mathrm{~b}$, the fitted $\mathrm{Cu} 2 \mathrm{p}_{3 / 2}$ spectrum showed two components at $932.9 \mathrm{eV}$ and $934.3 \mathrm{eV}$, which were identified as the characteristic signals of the metallic copper $\mathrm{Cu}^{0}$ and $\mathrm{CuO}$, respectively. It indicated that $\mathrm{Cu}$ did not participate in the form of nitrides in the coatings, which was in accordance with the XRD results (Figure 2a). In addition, the formation of $\mathrm{CuO}$ oxides had not been found in the Mo-Cu-V-N composite coatings, which would be due to the low content of $\mathrm{Cu}$ [20]. As seen in Figure 3c, the peak with a binding energy of $514.3 \mathrm{eV}$ was found in the V $2 p_{3 / 2}$ spectra, which was identified as the characteristic signal of VN. In Figure $3 d$, the N 1s spectrum can be deconvoluted into two peaks: a major peak at $397.6 \mathrm{eV}$ and a weak peak at $397.1 \mathrm{eV}$, corresponding to the $\mathrm{MoN}$ and $\mathrm{VN}$, respectively. 

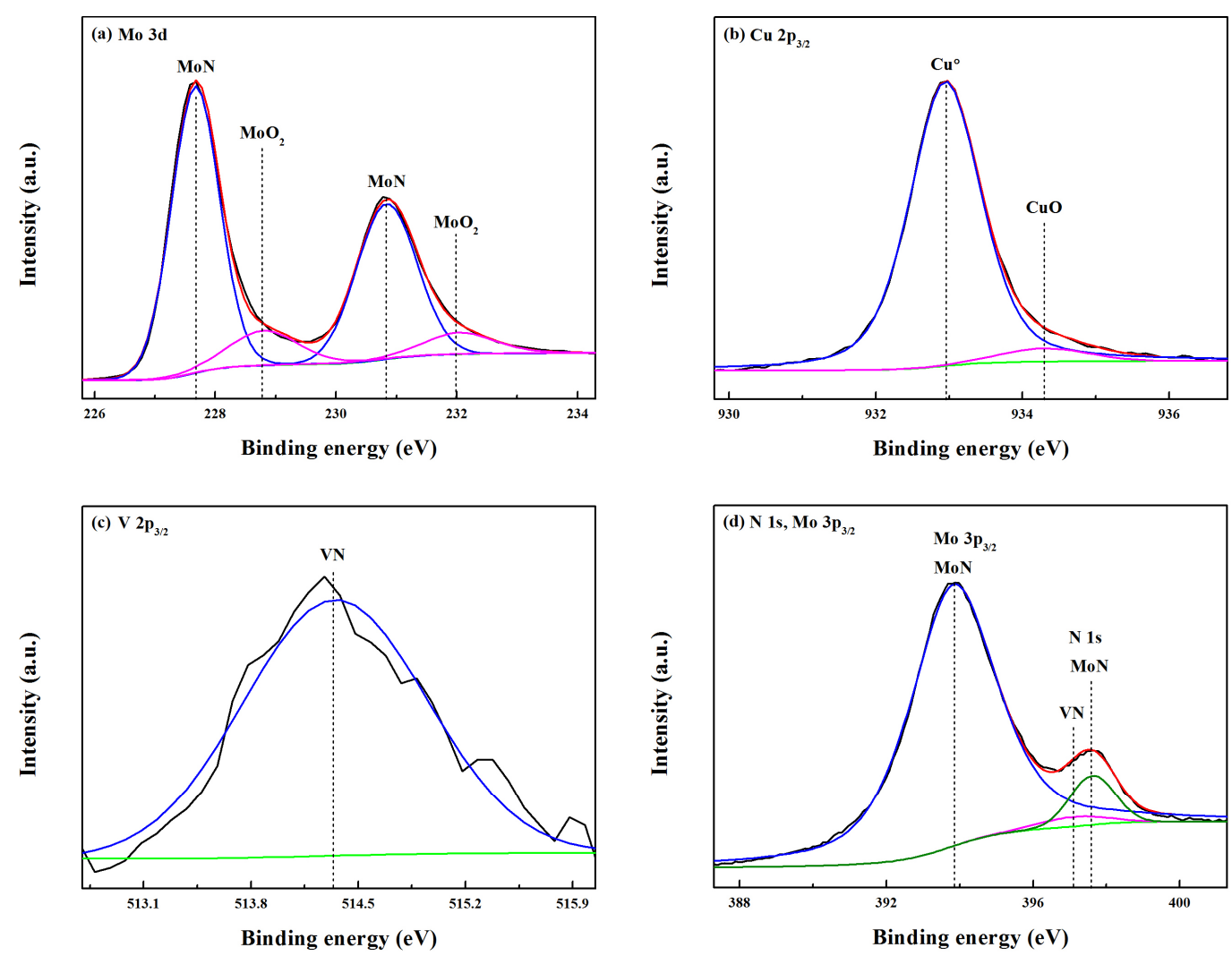

Figure 3. Fitted XPS spectra of Mo-Cu-V-N coating deposited at the $\mathrm{N}_{2}$ partial pressure of $0.11 \mathrm{~Pa}$ : (a) Mo 3d, (b) Cu 2 $\mathrm{p}_{3 / 2}$, (c) V 2 $\mathrm{p}_{3 / 2}$, and (d) N 1s, Mo 3 $\mathrm{p}_{3 / 2}$.

Figure 4 displays the cross-sectional SEM micrographs of $\mathrm{Mo}-\mathrm{Cu}-\mathrm{V}-\mathrm{N}$ composite coatings deposited at different $\mathrm{N}_{2}$ partial pressures. It can be clearly seen that all the coatings exhibited columnar-type structure. As shown in Figure 4a, the compact columnar microstructure can be clearly observed for the Mo-Cu-V-N coating deposited at the $\mathrm{N}_{2}$ partial pressure of $0.11 \mathrm{~Pa}$. With the increase of $\mathrm{N}_{2}$ partial pressure, much coarser columnar microstructure appeared and grew outward from the coating-substrate interface to the Mo-Cu-V-N coating surface (Figure $4 \mathrm{c}-\mathrm{e}$ ). This phenomenon can be explained by the higher nitrogen concentration where the sputtering yield of metal atoms is more reduced, which would lead to the effect of high-energy ions bombarding being decreased during the deposition. Based on the coating thickness measured from cross-sectional SEM micrographs, it was found that the coating thickness decreased from 2.4 to $2.1 \mu \mathrm{m}$ with an increase in the $\mathrm{N}_{2}$ partial pressure from 0.11 to $0.35 \mathrm{~Pa}$. Since the total working pressure was held constant and the $\mathrm{N}_{2}$ partial pressure was increased, the sputtering Ar ions was then decreased, resulting in increased target poisoning and, thus, a decreased deposition rate. In addition, it had been reported that the higher nitrogen partial pressure was increased, more current was carried by nitrogen ion in the plasma, thus the depositing rate is reduced [29].

Figure 5 presents the residual stress of $\mathrm{Mo}-\mathrm{Cu}-\mathrm{V}-\mathrm{N}$ composite coatings as a function of the $\mathrm{N}_{2}$ partial pressure. It can be clearly seen that the compressive residual stress of the coatings decreased first from $-1.10 \mathrm{GPa}$ to $-0.84 \mathrm{GPa}$ with an increase in the $\mathrm{N}_{2}$ partial pressure from 0.11 to $0.14 \mathrm{~Pa}$, which would be mainly due to the initial increase of $\mathrm{Cu}$ content in the coatings. The decrease in residual stress would be due to the presence of a compliant copper phase in the coatings [14]. As the $\mathrm{N}_{2}$ partial pressure was further increased to $0.35 \mathrm{~Pa}$, a slowly decreasing compressive residual stress was observed down to $-0.68 \mathrm{GPa}$. As the columnar microstructure became coarser at higher $\mathrm{N}_{2}$ partial pressures, the residual stress induced by sputtering could be released, resulting in a decrease of the compressive residual stress. Meanwhile, the decrease in the intrinsic compressive residual stress could 
be associated with the absence of a significant number of high-energy ions bombarding the growing film during deposition process at higher nitrogen partial pressures [30].
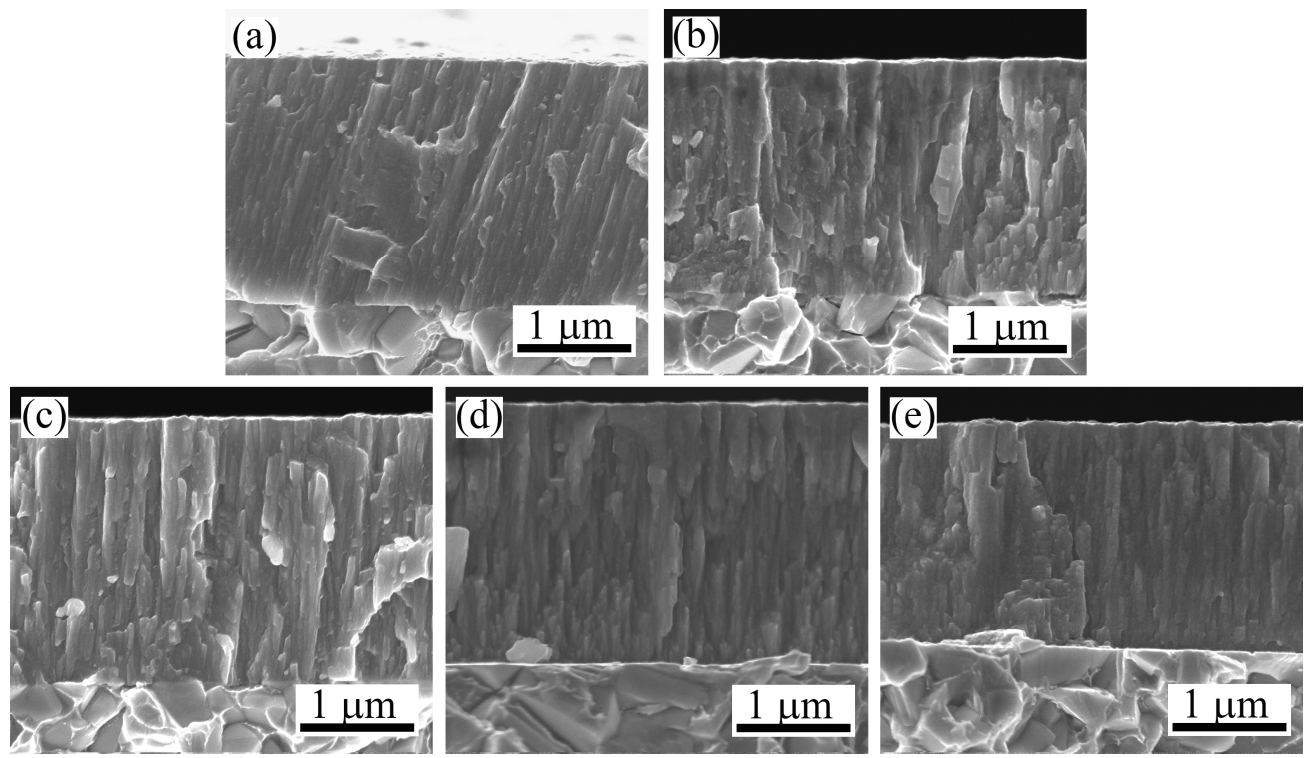

Figure 4. Cross-sectional SEM micrographs of Mo-Cu-V-N composite coatings deposited at various $\mathrm{N}_{2}$ partial pressures: (a) $0.11 \mathrm{~Pa}$, (b) $0.14 \mathrm{~Pa}$, (c) $0.17 \mathrm{~Pa}$, (d) $0.25 \mathrm{~Pa}$ and (e) $0.35 \mathrm{~Pa}$.

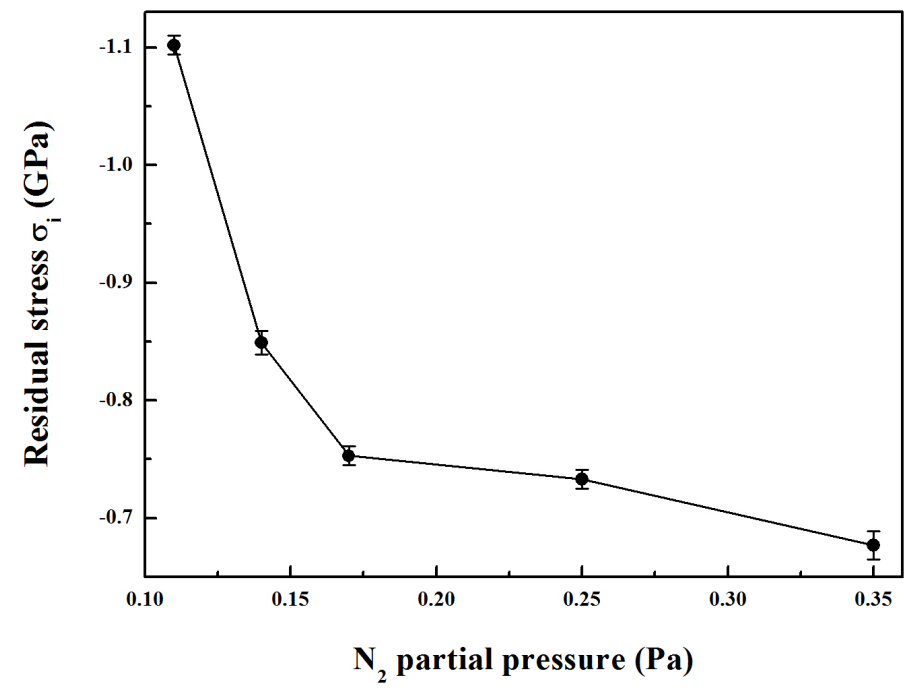

Figure 5. Residual stress of Mo- $\mathrm{Cu}-\mathrm{V}-\mathrm{N}$ coatings as a function of $\mathrm{N}_{2}$ partial pressure.

The hardness and elastic modulus of Mo-Cu-V-N composite coatings as a function of $\mathrm{N}_{2}$ partial pressure is shown in Figure 6. Both the hardness and modulus showed the same trend. With increasing the $\mathrm{N}_{2}$ partial pressure from 0.11 to $0.35 \mathrm{~Pa}$, the hardness and elastic modulus decreased from 19.0 GPa and $393 \mathrm{GPa}$ to $15.5 \mathrm{GPa}$ and $316 \mathrm{GPa}$, respectively. Therefore, the hardness exhibited a decrease instead of rebound as the $\mathrm{N}_{2}$ partial pressure increased to $0.35 \mathrm{~Pa}$ when compared to the $\mathrm{Mo}-\mathrm{Cu}-\mathrm{V}-\mathrm{N}$ coatings in previous studies [20]. The reduction of the hardness at higher copper concentrations was reported to be related with grain boundary sliding due to the weak interface of $n c-\mathrm{Mo}_{2} \mathrm{~N} / \mathrm{Cu}$ or large amount of $\mathrm{Cu}$ segregation [31]. In this present work, the compressive residual stress and microstructure of the coatings mainly determined the variation tendency of the hardness of the coatings with $\mathrm{N}_{2}$ partial pressure. The decrease in hardness could be explained as follows: (1) At higher partial pressures, the decrease in compressive residual stress would play an important role in the hardness of coatings. 
It is generally observed that a high compressive residual stress usually accounts for high hardness values, the decrease in hardness would be due to the relaxation of the compressive residual stress [32]. (2) The coarser columnar microstructure at high $\mathrm{Cu}$ content can also be assumed to contribute to the lower hardness as well as to the lower elastic modulus. Moreover, the preferred orientation (200) peak was significantly broader at higher nitrogen partial pressures indicating grain refinement, which was not the main influence factor of the hardness of $\mathrm{Mo}-\mathrm{Cu}-\mathrm{V}-\mathrm{N}$ composite coatings with high $\mathrm{Cu}$ content.

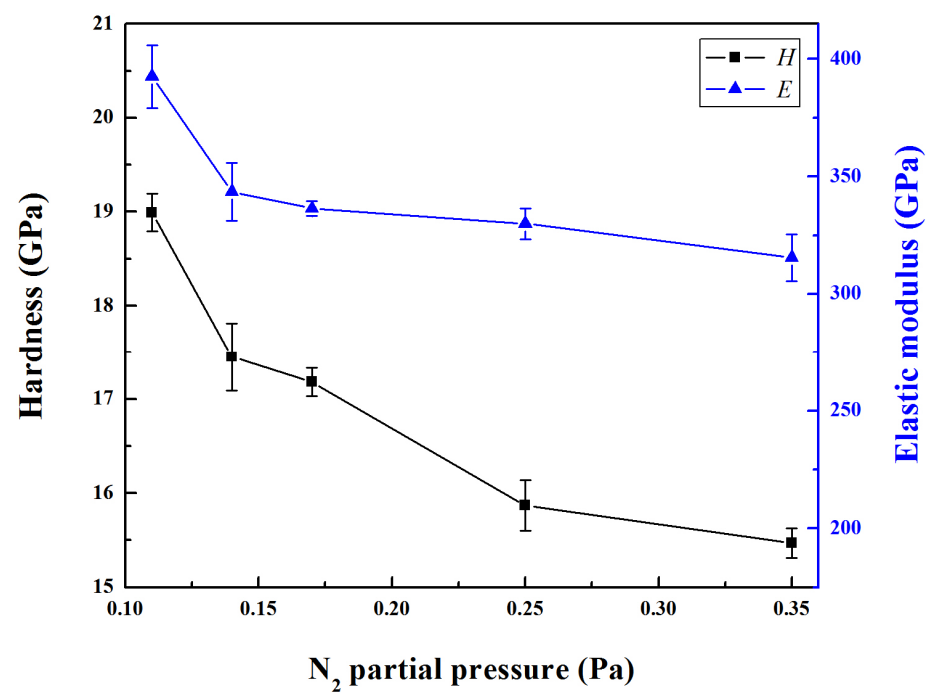

Figure 6. Hardness and elastic modulus of $\mathrm{Mo}-\mathrm{Cu}-\mathrm{V}-\mathrm{N}$ coatings as a function of $\mathrm{N}_{2}$ partial pressure.

\subsection{Tribological Properties}

Figure 7 reveals the friction coefficient curves of Mo-Cu-V-N composite coatings after tribological tests at $25^{\circ} \mathrm{C}$ and $400{ }^{\circ} \mathrm{C}$, respectively. In a similar ball-on-disc dry sliding wear of a sputtered nitride coating, the running-in friction would be attributed to the initial wear particle generation and the subsequent formation of a tribofilm [33]. It was found that all the friction coefficient curves rapidly increased in the initial running-in phase, and reached steady-state after sliding about 1000 cycles at $25{ }^{\circ} \mathrm{C}$. However, the obvious fluctuation was observed in the friction curve when the wear temperature was increased up to $400{ }^{\circ} \mathrm{C}$, especially for the Mo-Cu-V-N composite coating deposited at the $\mathrm{N}_{2}$ partial pressure of $0.35 \mathrm{~Pa}$. If a stable oxide layer were not present in the wear track, the friction coefficient curve should exhibit significant fluctuations associated to the formation and loss of the oxides that are expected to form under these experimental conditions [34]. As shown in Figure 7c, the average friction coefficient varied in the small range of $0.29-0.31$ when sliding at $25^{\circ} \mathrm{C}$. When the wear temperature was increased up to $400{ }^{\circ} \mathrm{C}$, the average friction coefficient first increased from 0.43 to 0.51 as the $\mathrm{N}_{2}$ partial pressure increased from 0.11 to $0.17 \mathrm{~Pa}$, and then remained almost constant.

A comparison of three-dimensional morphologies of the wear tracks after the coatings were tested at different temperatures is shown in Figure 8. Grooves with different depths and widths were observed on the wear tracks of the Mo-Cu-V-N composite coatings after tribological tests at different temperatures. When sliding at $25^{\circ} \mathrm{C}$, it can be clearly seen that the wear tracks were much narrower and shallower, and some "plow furrow" formed along the counterpart sliding direction in the area of wear tracks, indicating that abrasive wear occurred at $25^{\circ} \mathrm{C}$. In addition, the wear track widths increased sharply with the increase of wear temperature and $\mathrm{N}_{2}$ partial pressure at the high temperature of $400{ }^{\circ} \mathrm{C}$ (Figure $8 \mathrm{c}, \mathrm{d}$ ), indicating the decrease of wear resistant. Figure 9 displays the surface images of the wear tracks of Mo-Cu-V-N composite coatings after tribological tests. It was found that the surfaces of the wear tracks were relatively smooth when sliding at $25^{\circ} \mathrm{C}$, and some wear debris accumulated at the boundary of the wear tracks. However, the surfaces of the wear tracks became rougher when the wear temperature was increased up to $400{ }^{\circ} \mathrm{C}$, as shown in Figure $9 \mathrm{c}, \mathrm{d}$. 
Moreover, some wear particles also appeared on the surfaces of wear tracks, which could account for the increase of friction coefficient at high temperatures. It was reported that the wear particles generated were entrapped subsequently in the sliding contact, causing three-body sliding/rolling abrasive wear of the coating surface and fracturing of the wear particles themselves [35].
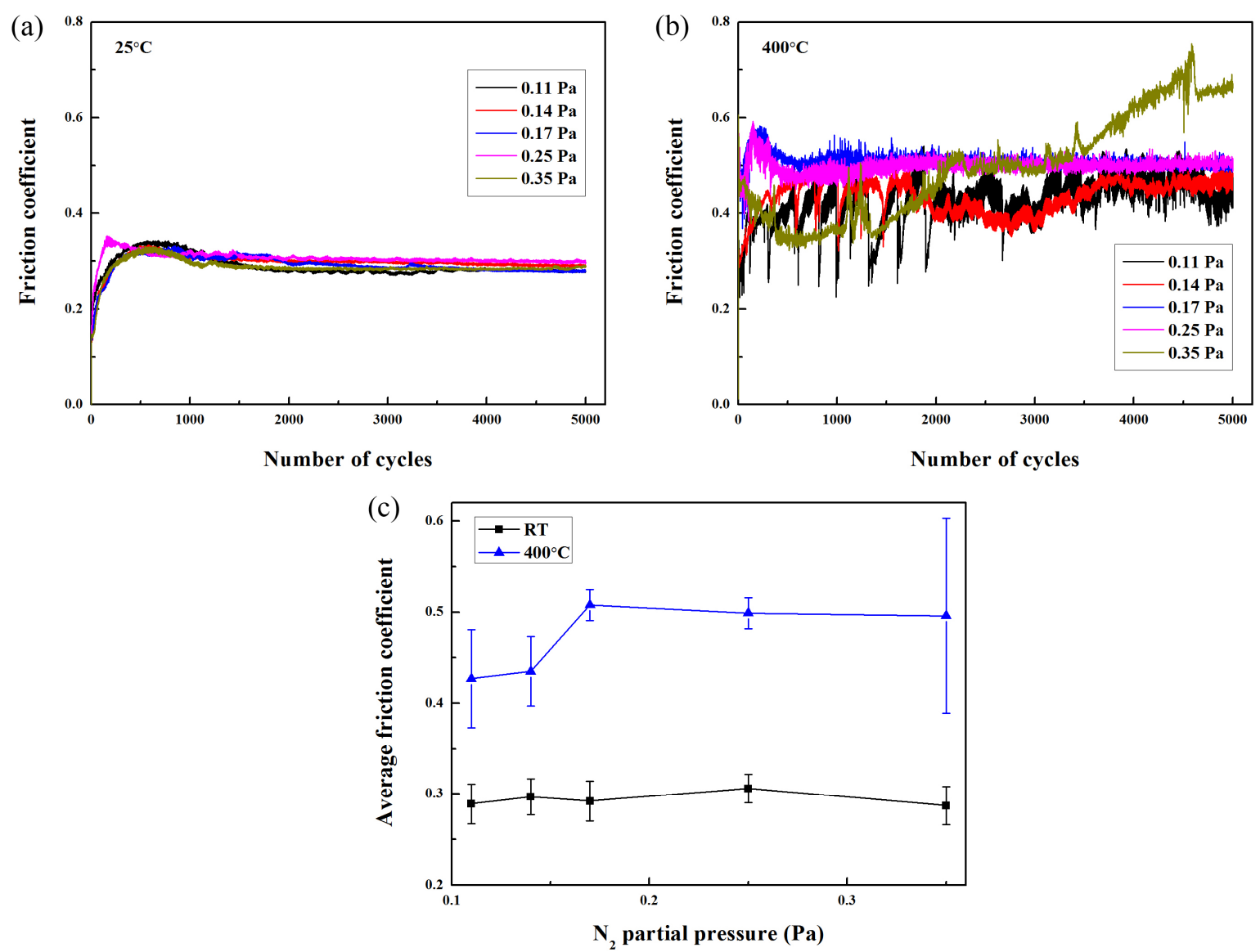

Figure 7. Friction coefficient curves of $\mathrm{Mo}-\mathrm{Cu}-\mathrm{V}-\mathrm{N}$ coatings tested at (a) $25{ }^{\circ} \mathrm{C}$ and (b) $400{ }^{\circ} \mathrm{C}$; (c) the average friction coefficient as a function of $\mathrm{N}_{2}$ partial pressure.
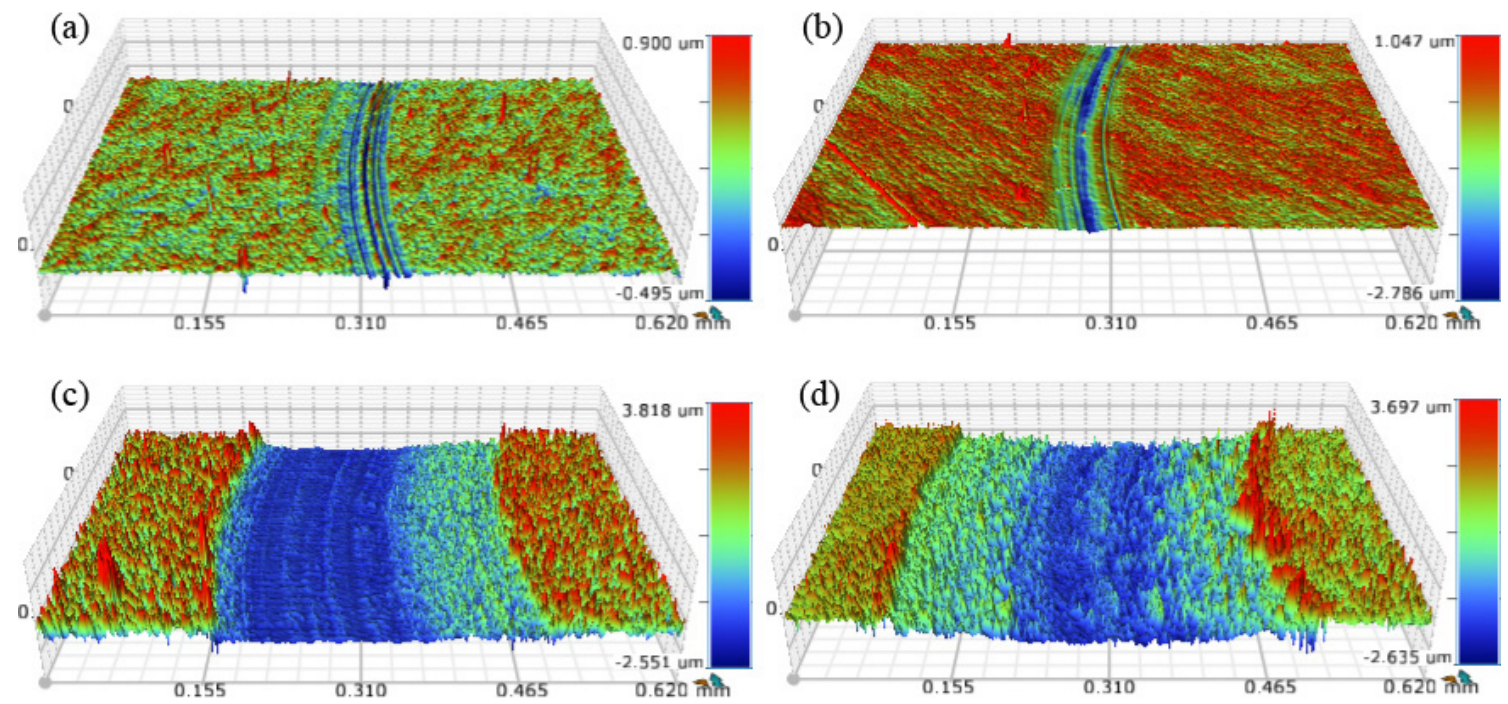

Figure 8. Three-dimensional morphologies of the wear tracks: (a) $25^{\circ} \mathrm{C}, 0.11 \mathrm{~Pa}$; (b) $25^{\circ} \mathrm{C}, 0.25 \mathrm{~Pa}$; (c) $400{ }^{\circ} \mathrm{C}, 0.11 \mathrm{~Pa}$ and (d) $400{ }^{\circ} \mathrm{C}, 0.25 \mathrm{~Pa}$. 

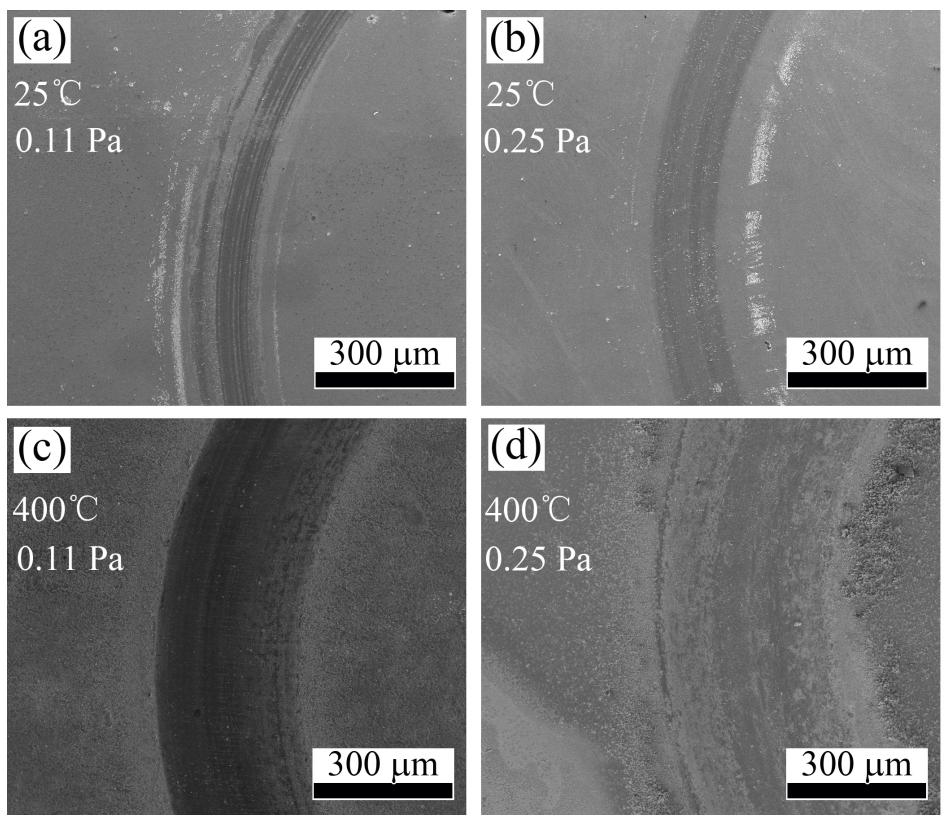

Figure 9. SEM images of the wear tracks after tribological tests: (a) $25^{\circ} \mathrm{C}, 0.11 \mathrm{~Pa}$; (b) $25^{\circ} \mathrm{C}, 0.25 \mathrm{~Pa}$; (c) $400{ }^{\circ} \mathrm{C}, 0.11 \mathrm{~Pa}$ and (d) $400{ }^{\circ} \mathrm{C}, 0.25 \mathrm{~Pa}$.

To analyze the wear mechanism of the Mo-Cu-V-N composite coatings at different temperatures and $\mathrm{N}_{2}$ partial pressures, the chemical composition of the wear tracks on the worn surfaces were determined by EDS analysis. As shown in Table 2, the EDS analysis indicated that some O element was detected in the wear tracks at $25^{\circ} \mathrm{C}$, which was in the small range of $11.5-13.8$ at.\%, indicating that a tribo-oxidation phenomenon occurred during the sliding test. As the wear temperature was increased up to $400{ }^{\circ} \mathrm{C}$, the $\mathrm{O}$ content in the wear track was increased up to 56.0-61.8 at.\%, while the $\mathrm{N}$ content in the wear track decreased sharply to 9.4-12.2 at.\%, indicating that the Mo-Cu-V-N composite coatings had been oxidized severely. The weak bonds between molybdenum and nitrogen easily broke at elevated temperatures, which would lead to the loss of nitrogen and pronounced oxidation [36]. Therefore, the oxidation wear became the main wear mechanism when sliding at the high temperature of $400{ }^{\circ} \mathrm{C}$. In addition, it could be found that less $\mathrm{O}$ contents and more $\mathrm{N}$ contents were detected in the wear tracks with the increase of $\mathrm{N}_{2}$ partial pressure, which could lead to better lubrications at lower nitrogen partial pressures. This is similar to an investigation by Wang et al. which showed the $\mathrm{MoN}_{\mathrm{x}}$ coating with higher $\mathrm{N}$ content would be much more difficult to be oxidized in air [28].

Table 2. Chemical composition of the wear tracks after tribological tests at different temperatures.

\begin{tabular}{ccccccc}
\hline \multirow{2}{*}{ Temperature } & \multirow{2}{*}{$\begin{array}{c}\mathbf{N}_{2} \text { Partial } \\
\text { Pressure }\end{array}$} & \multicolumn{5}{c}{ Chemical Composition (at.\%) } \\
\cline { 3 - 7 } & & $\mathbf{M o}$ & $\mathbf{C u}$ & $\mathbf{V}$ & $\mathbf{N}$ & $\mathbf{O}$ \\
\hline \multirow{2}{*}{$25^{\circ} \mathrm{C}$} & $0.11 \mathrm{~Pa}$ & 36.20 & 14.60 & 2.25 & 33.18 & 13.77 \\
& $0.25 \mathrm{~Pa}$ & 33.43 & 14.55 & 2.55 & 38.00 & 11.48 \\
\hline \multirow{2}{*}{$400{ }^{\circ} \mathrm{C}$} & $0.11 \mathrm{~Pa}$ & 20.82 & 6.39 & 1.68 & 9.35 & 61.77 \\
& $0.25 \mathrm{~Pa}$ & 22.26 & 8.01 & 1.45 & 12.24 & 56.03 \\
\hline
\end{tabular}

After the tribological tests at $25{ }^{\circ} \mathrm{C}$ and $400{ }^{\circ} \mathrm{C}$, the XPS analysis was employed on the area A and $\mathrm{B}$ in the wear tracks (Figure $9 \mathrm{a}, \mathrm{c}$ ) to determine the chemical bonding states of the oxide scales. As shown in Figure 10, the asymmetric Mo 3d peaks consisted of two main peaks at binding energies (BE) of $228.1 \mathrm{eV}$ and $231.2 \mathrm{eV}$, and two smaller peaks at binding energies of $228.8 \mathrm{eV}$ and $231.9 \mathrm{eV}$, corresponding to the $\mathrm{Mo} 3 \mathrm{~d}_{5 / 2}$ and $\mathrm{Mo} 3 \mathrm{~d}_{3 / 2}$ electrons in the $\mathrm{MoN}$ and $\mathrm{MoO}_{2}$, respectively. Therefore, the Mo 3d, as well as Cu 2p, and N 1s XPS core level spectra of the worn surfaces showed similar 
results to the XPS analysis of the as-deposited Mo-Cu-V-N coating (as shown in Figure 3). However, the fitted $\mathrm{V} 2 \mathrm{p}_{3 / 2}$ spectrum with two peaks centered at binding energies of $514.3 \mathrm{eV}$ and $516.2 \mathrm{eV}$, which corresponded to $\mathrm{VN}$ and $\mathrm{V}_{2} \mathrm{O}_{5}$, respectively (Figure 10c). It indicated that the vanadium nitride phase existed in the Mo- $\mathrm{Cu}-\mathrm{V}-\mathrm{N}$ coatings was partially oxidized to form the lubricious oxide of $\mathrm{V}_{2} \mathrm{O}_{5}$. Figure 11 shows the fitted XPS spectra of the wear track of Mo-Cu-V-N composite coating after tribological test at $400{ }^{\circ} \mathrm{C}$. As shown in Figure 11a, the Mo 3d peaks shifted towards high binding energies and contain two possible components at the binding energies of $229.7 / 231.6 \mathrm{eV}$ and 232.6/235.1 eV, originating from Mo $3 \mathrm{~d}_{5 / 2}$ and $\mathrm{Mo} 3 \mathrm{~d}_{3 / 2}$ electrons in $\mathrm{MoN}$ and $\mathrm{MoO}_{3} / \mathrm{CuMoO}_{4}$, respectively. It was difficult to distinguish the $\mathrm{MoO}_{3}(232.5 \pm 0.3 \mathrm{eV})$ and $\mathrm{CuMoO}_{4}(232.7 \pm 0.3 \mathrm{eV})$ species by Mo $3 \mathrm{~d}_{3 / 2}$ spectrum because the peak positions are too close [21]. In Figure 11b, the fitted $\mathrm{Cu}$ $2 \mathrm{p}_{3 / 2}$ spectrum showed two components at $932.7 \mathrm{eV}$ and $934.1 \mathrm{eV}$, which can be assigned to the spectra of $\mathrm{Cu}^{0}$ and $\mathrm{CuMoO}_{4}$, respectively. It was reported that $\mathrm{CuMoO}_{4}$ possesses better self-lubricating behavior than $\mathrm{MoO}_{3}$ due to the high difference of ionic potentials existing between $\mathrm{MoO}_{3}$ and $\mathrm{CuO}$ $(8.2-2.8=5.4)$ [37]. Therefore, by considering both the Mo $3 \mathrm{~d}$ spectrum and $\mathrm{Cu} 2 \mathrm{p}_{3 / 2}$ spectrum in Figure $11 \mathrm{a}, \mathrm{b}$, it can be assumed that mainly $\mathrm{MoO}_{3}$ oxides formed in the wear track for Mo-Cu-V-N composite coating. In addition, it can be clearly seen that mainly $\mathrm{MoO}_{3} / \mathrm{CuMoO}_{4}$ and minor $\mathrm{MoN}$ species were found in the XPS peaks when the wear temperature was increased up to $400{ }^{\circ} \mathrm{C}$, which could be due to the loss of nitrogen and pronounced oxidation at high temperatures for the Mo-Cu-V-N composite coatings. It was in accordance with the rapid increase of $\mathrm{O}$ content in the wear tracks as shown in Table 2. Similar results were also found for the $\mathrm{VN}$ and $\mathrm{V}_{2} \mathrm{O}_{5}$ species in the $\mathrm{V} 2 \mathrm{p}_{3 / 2}$ XPS peak as seen in Figure 11c. Meanwhile, the Mo $3 p_{3 / 2}$ peak shifted towards high binding energies and the peak intensity decreased sharply when the wear temperature was increased up to $400{ }^{\circ} \mathrm{C}$ (Figure 11d), which was in accordance with the decrease of Mo content in the wear track.
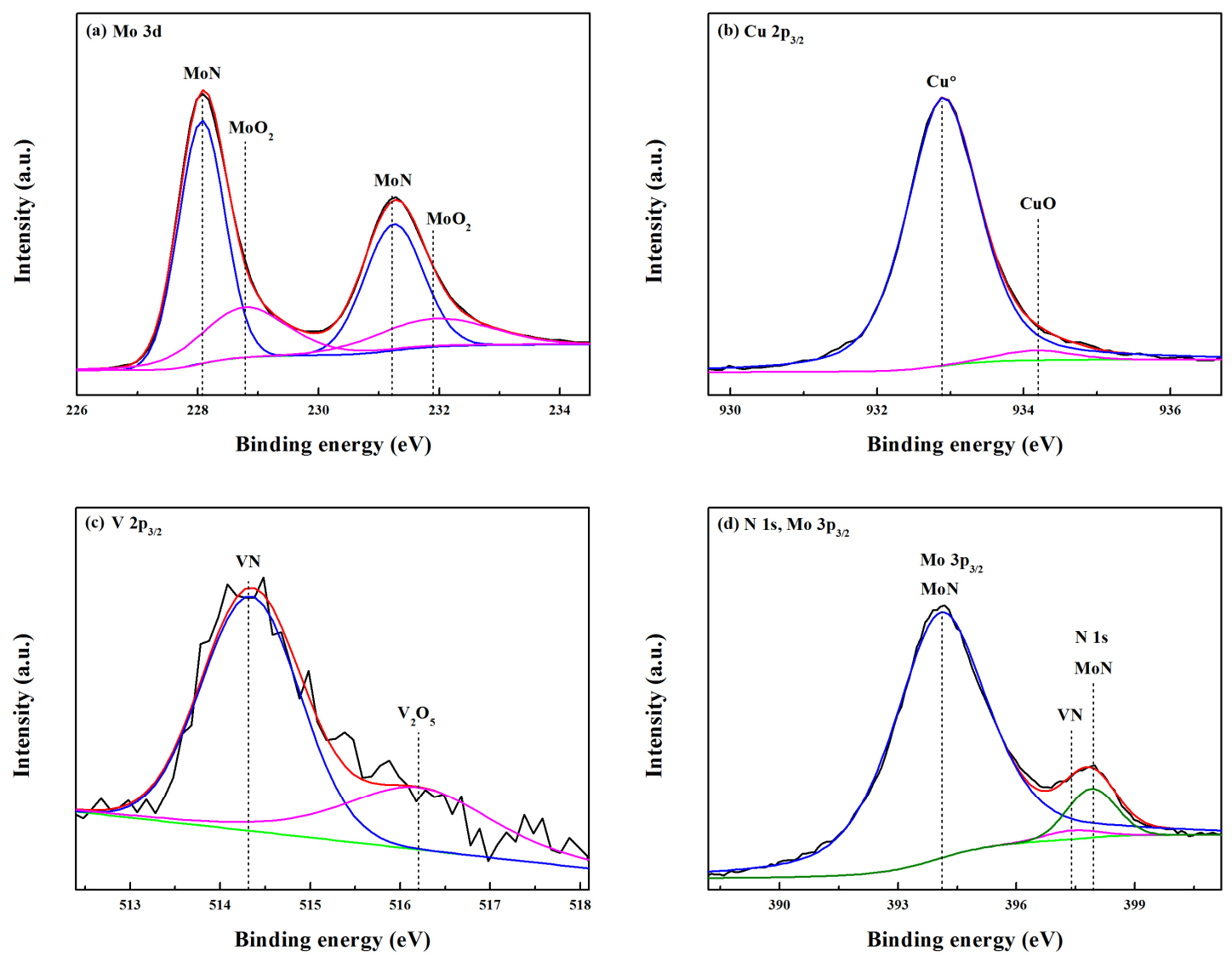

Figure 10. Fitted XPS spectra of the wear track of $\mathrm{Mo}-\mathrm{Cu}-\mathrm{V}-\mathrm{N}$ composite coating after tribological test at $25{ }^{\circ} \mathrm{C}$ : (a) Mo $3 \mathrm{~d},(\mathbf{b}) \mathrm{Cu} 2 \mathrm{p}_{3 / 2}$, (c) V 2 $\mathrm{p}_{3 / 2}$, and (d) N 1s, Mo 3 $\mathrm{p}_{3 / 2}$. 

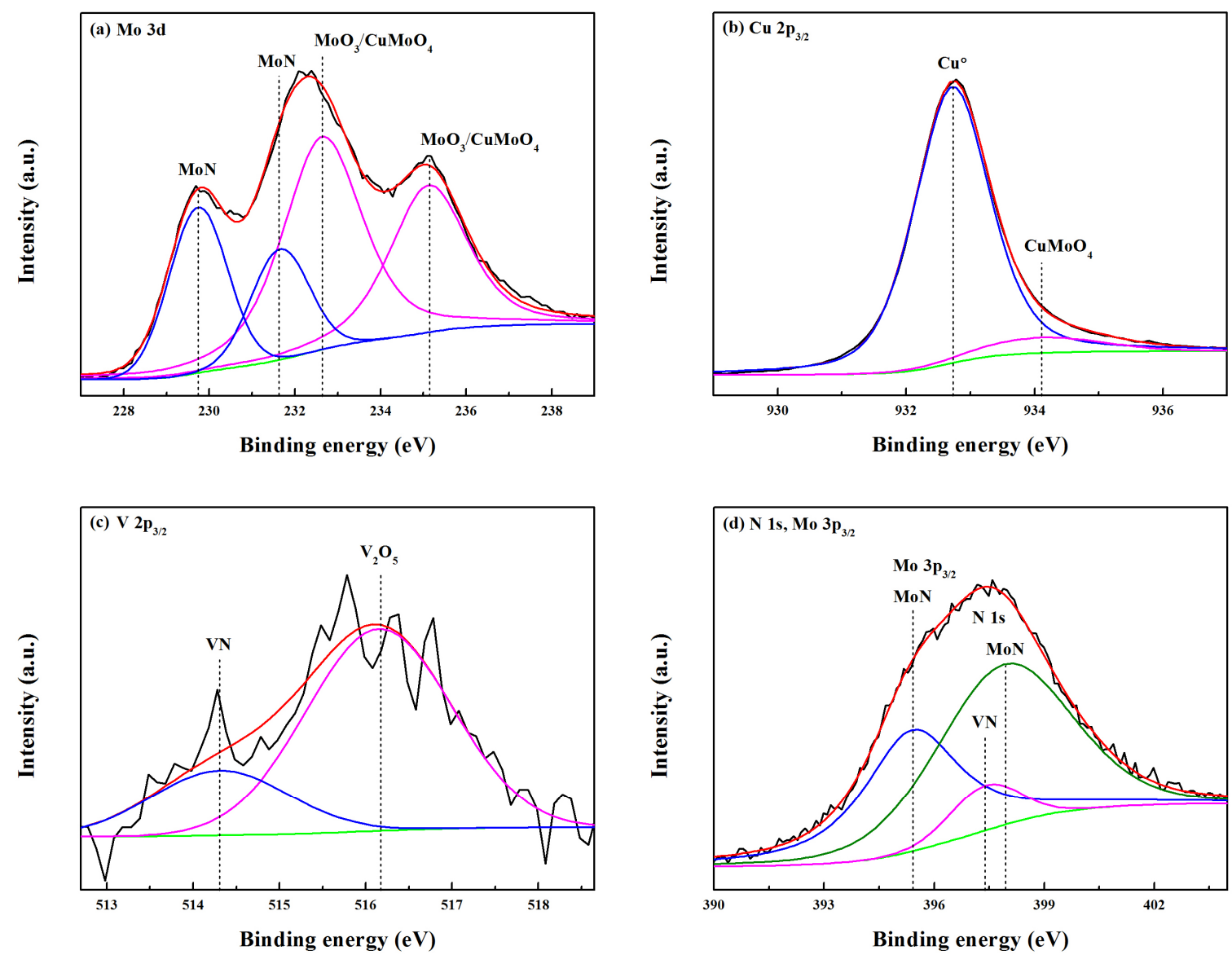

Figure 11. Fitted XPS spectra of the wear track of $\mathrm{Mo}-\mathrm{Cu}-\mathrm{V}-\mathrm{N}$ composite coating after tribological test at $400{ }^{\circ} \mathrm{C}$ : (a) Mo 3d, (b) Cu 2 $\mathrm{p}_{3 / 2}$, (c) V 2 $\mathrm{p}_{3 / 2}$, and (d) N 1s, Mo 3 $\mathrm{p}_{3 / 2}$.

To further investigate the chemical structure evolution process induced by the increased in wear temperature, the bond fractions were calculated based on the corresponding peak areas of the fitted XPS peaks. Figure 12 shows the Mo-N, Mo-O, Cu, Cu-O, V-N, and V-O bond fractions of Mo-Cu-V-N composite coatings deposited at the $\mathrm{N}_{2}$ partial pressure of $0.11 \mathrm{~Pa}$. The $\mathrm{Mo}-\mathrm{O}, \mathrm{Cu}-\mathrm{O}$, and $\mathrm{V}-\mathrm{O}$ bonds were found in the $\mathrm{Mo}-\mathrm{Cu}-\mathrm{V}-\mathrm{N}$ coating after the friction test conducted at $25^{\circ} \mathrm{C}$, which would be due to the tribo-oxidation phenomenon that occurred during the sliding test. It can be seen that the Mo-N, $\mathrm{Cu}$, and V-N bond fractions were $69.5 \%, 97.0 \%$, and $67.2 \%$, respectively, which are higher than those of the oxide bonds. It indicated that the Mo-Cu-V-N composite coating had been oxidized slightly during sliding at room temperature, which was in accordance with the EDS analysis as shown in Table 2. When the wear temperature was further increased to $400{ }^{\circ} \mathrm{C}$, the $\mathrm{Mo}-\mathrm{N}, \mathrm{Cu}$, and V-N bond fractions decreased to $31.5 \%, 92.7 \%$, and $23.4 \%$, while the $\mathrm{Mo}-\mathrm{O}, \mathrm{Cu}-\mathrm{O}$, and $\mathrm{V}-\mathrm{O}$ bond fractions increased up to $68.5 \%, 7.3 \%$, and $76.6 \%$, respectively. It indicated that the Mo-Cu-V-N composite coatings had been oxidized severely during sliding at the high temperature of $400{ }^{\circ} \mathrm{C}$.

Figure 13a depicts the maximum wear track depth with respect to the wear temperature and $\mathrm{N}_{2}$ partial pressure. A relatively low wear track depth in the small range of $0.05-0.11 \mu \mathrm{m}$ was achieved after the tribological test at $25^{\circ} \mathrm{C}$. However, when the wear temperature was increased up to $400{ }^{\circ} \mathrm{C}$, the maximum wear track depth increased sharply from 0.46 to $1.69 \mu \mathrm{m}$ while the $\mathrm{N}_{2}$ partial pressure increased from 0.11 to $0.35 \mathrm{~Pa}$. It can be seen that the maximum wear track depths were less than the coating thickness, indicating that all the coatings were not worn out to failure even at the high temperature of $400{ }^{\circ} \mathrm{C}$. The different wear track depths of the coatings could be due to the different friction and wear behaviors, which could directly influence the wear rate of the coatings. As shown in Figure $13 \mathrm{~b}$, after the tribological test at $25^{\circ} \mathrm{C}$, the wear rate of $\mathrm{Mo}-\mathrm{Cu}-\mathrm{V}-\mathrm{N}$ composite coatings first 
decreased slightly from $7.5 \times 10^{-8}$ to $6.6 \times 10^{-8} \mathrm{~mm}^{3} / \mathrm{N} \cdot \mathrm{m}$ by increasing the $\mathrm{N}_{2}$ partial pressure from 0.11 to $0.14 \mathrm{~Pa}$, which would be due to the initial increase of $\mathrm{Cu}$ content in the coatings and the release of residual stress. The wear rate was correlated to the adhesion energy, which was directly related to the residual stress and ultimately, the initial copper content [14]. When the $\mathrm{N}_{2}$ partial pressure further increased to $0.35 \mathrm{~Pa}$, the wear rate followed by an increase to $14.9 \times 10^{-8} \mathrm{~mm} / \mathrm{N} \cdot \mathrm{m}$, which could be mainly due to the decrease of mechanical properties at higher nitrogen partial pressures. When compared to the Mo-Cu-V-N coatings with low $\mathrm{Cu}$ content [20], a much lower wear rate of $10^{-8} \mathrm{~mm}^{3} / \mathrm{N} \cdot \mathrm{m}$ was achieved in this work, which was similar to the wear rate of the Al-DLC films deposited by a hybrid beams system comprising an anode-layer ion source and a magnetron sputtering unit [38]. The typical wear rate values for solid lubricants with moderate wear resistance were between $10^{-7}$ and $10^{-5} \mathrm{~mm}^{3} / \mathrm{N} \cdot \mathrm{m}[14,39]$. Therefore, the excellent tribological properties could be attributed to the mixed lubricious oxides of $\mathrm{MoO}_{2}, \mathrm{CuO}$ and $\mathrm{V}_{2} \mathrm{O}_{5}$ formed during tribo-oxidation, which usually lead to lower friction coefficients and better wear resistance [15]. When the wear temperature was increased up to $400{ }^{\circ} \mathrm{C}$, despite of the forming of lubricious oxides of $\mathrm{MoO}_{3} / \mathrm{CuMoO}_{4}$ and $\mathrm{V}_{2} \mathrm{O}_{5}$, the high wear rate increased from $3.1 \times 10^{-6}$ to $13.5 \times 10^{-6} \mathrm{~mm}^{3} / \mathrm{N} \cdot \mathrm{m}$ with increasing the $\mathrm{N}_{2}$ partial pressure, which was higher two orders of magnitude than of at $25^{\circ} \mathrm{C}$. It could be mainly due to the loss of nitrogen and pronounced oxidation at high temperatures, which led the wear mechanism to be transformed from mild oxidation wear to severe oxidation wear.

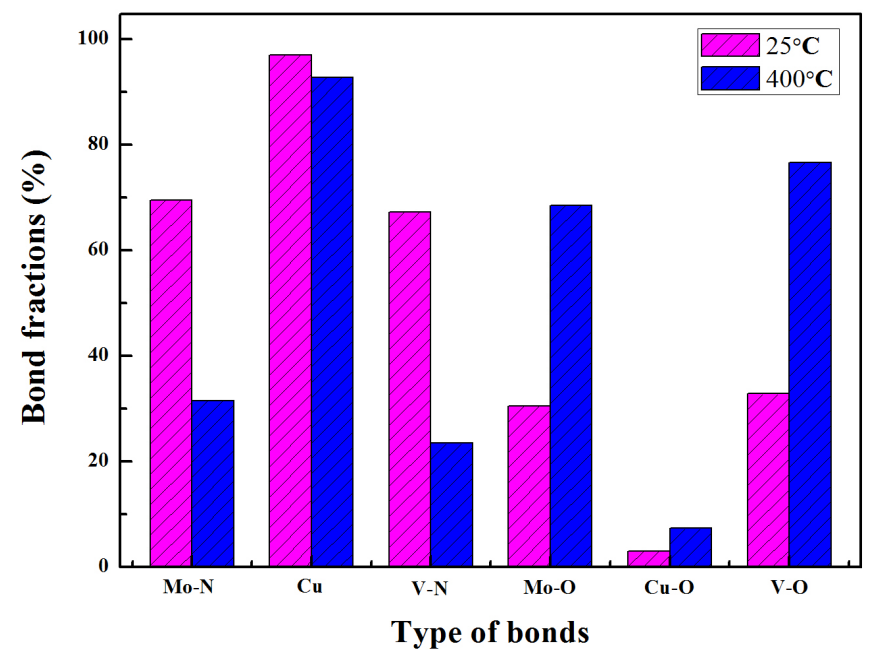

Figure 12. The Mo-N, Mo-O, $\mathrm{Cu}, \mathrm{Cu}-\mathrm{O}, \mathrm{V}-\mathrm{N}$ and $\mathrm{V}-\mathrm{O}$ bond fractions of $\mathrm{Mo}-\mathrm{Cu}-\mathrm{V}-\mathrm{N}$ composite coating after tribological tests at different temperatures.
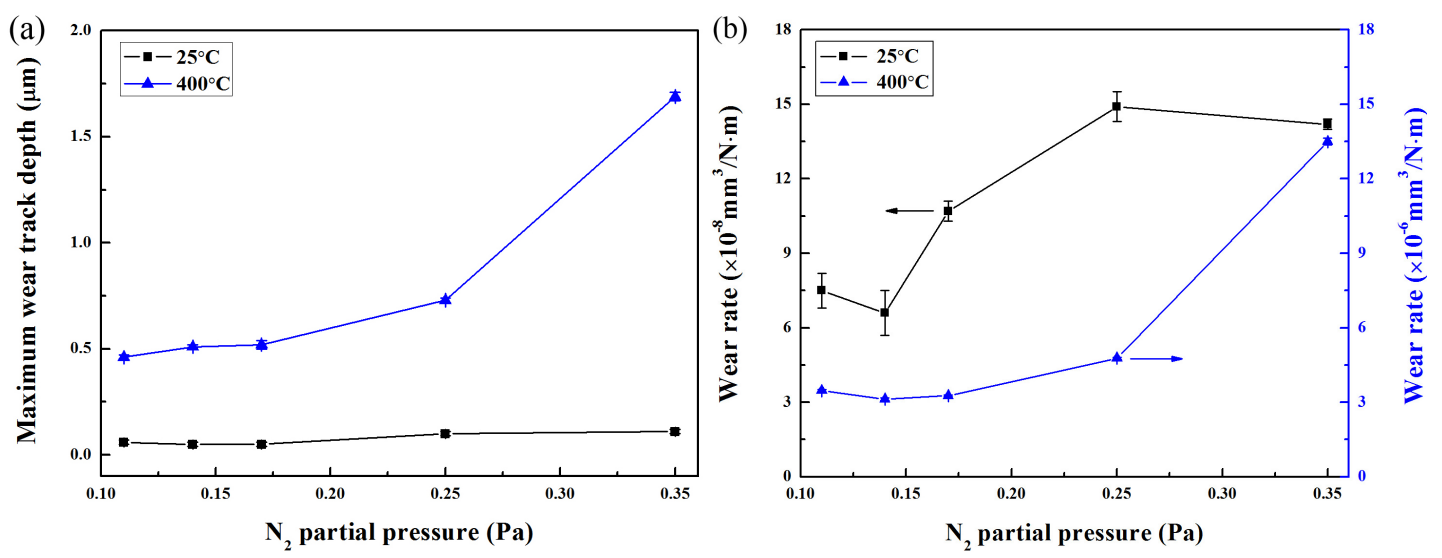

Figure 13. (a) Maximum wear track depth and (b) wear rate of $\mathrm{Mo}-\mathrm{Cu}-\mathrm{V}-\mathrm{N}$ composite coatings as a function of $\mathrm{N}_{2}$ partial pressure. 


\section{Conclusions}

In this study, the microstructure, mechanical properties and tribological properties of $\mathrm{Mo}-\mathrm{Cu}-\mathrm{V}-\mathrm{N}$ composite coatings with high $\mathrm{Cu}$ content of $\sim 18$ at.\% deposited at various $\mathrm{N}_{2}$ partial pressures were investigated. All the Mo-Cu-V-N composite coatings revealed FCC B1-MoN phase with a strong (200) preferred orientation, and the peak intensity decreased gradually with the increase of $\mathrm{N}_{2}$ partial pressure, and $\mathrm{Cu}$ was found to exist as metallic species in the Mo-Cu-V-N coatings. As the $\mathrm{N}_{2}$ partial pressure increased from 0.11 to $0.35 \mathrm{~Pa}$, the columnar microstructure became much coarser, which resulted in decrease of residual stress and hardness at high $\mathrm{Cu}$ content. The $\mathrm{Mo}-\mathrm{Cu}-\mathrm{V}-\mathrm{N}$ composite coatings with high $\mathrm{Cu}$ content exhibited a relatively low wear rate of $10^{-8} \mathrm{~mm}^{3} / \mathrm{N} \cdot \mathrm{m}$ at $25^{\circ} \mathrm{C}$. It was believed to be attributed to the mixed lubricious oxides of $\mathrm{MoO}_{2}, \mathrm{CuO}$ and $\mathrm{V}_{2} \mathrm{O}_{5}$ formed during tribo-oxidation. As the wear temperature was increased up to $400{ }^{\circ} \mathrm{C}$, the wear rate increased sharply up to $10^{-6} \mathrm{~mm}^{3} / \mathrm{N} \cdot \mathrm{m}$ despite of the formation of lubricious oxides of $\mathrm{MoO}_{3} / \mathrm{CuMoO}_{4}$ and $\mathrm{V}_{2} \mathrm{O}_{5}$, which was two orders of magnitude higher than that of at $25^{\circ} \mathrm{C}$. It could be due to the loss of nitrogen and pronounced oxidation at high temperature, which led to the transformation of the wear mechanism from mild oxidation wear to severe oxidation wear.

Acknowledgments: The work was supported in part by the projects of the National Natural Science Foundation of China (51522502, 51275095), China Postdoctoral Science Foundation funded project (2016M600641) and Guangdong Natural Science Funds (2014A030311002, 2016A050502056).

Author Contributions: Qimin Wang conceived and designed the experiments; Rui Wang and Xing Zhong performed the experiments; Haijuan Mei analyzed the data; Qimin Wang contributed reagents/materials/ analysis tools; Wei Dai and Haijuan Mei wrote the paper.

Conflicts of Interest: The authors declare no conflict of interest. The founding sponsors had no role in the design of the study; in the collection, analyses, or interpretation of data; in the writing of the manuscript, and in the decision to publish the results.

\section{References}

1. Münz, W.D. TiAlN Films: An Alternative to TiN Coatings. J. Vac. Sci. Technol. A 1986, 4, 2717-2725. [CrossRef]

2. PalDey, S.; Deevi, S.C. Single layer and multilayer wear resistant coatings of (Ti,Al)N: A review. Mater. Sci. Eng. A 2003, 342, 58-79. [CrossRef]

3. Gilmore, R.; Baker, M.A.; Gibson, P.N.; Gissler, W.; Stoiber, M.; Losbichler, P.; Mitterer, C. Low-friction TiN-MoS 2 coatings produced by dc magnetron co-deposition. Surf. Coat. Technol. 1998, 108-109, 345-351. [CrossRef]

4. Stoiber, M.; Badisch, E.; Lugmair, C.; Mitterer, C. Low-friction TiN coatings deposited by PACVD. Surf. Coat. Technol. 2003, 163-164, 451-456. [CrossRef]

5. Erdemir, A.; Halter, M.; Fenske, G.R. Preparation of ultralow-friction surface films on vanadium diboride. Wear 1997, 205, 236-239. [CrossRef]

6. Badisch, E.; Fontalvo, G.A.; Stoiber, M.; Mitterer, C. Tribological behavior of PACVD TiN coatings in the temperature range up to $500^{\circ} \mathrm{C}$. Surf. Coat. Technol. 2003, 163-164, 585-590. [CrossRef]

7. Storz, O.; Gasthuber, H.; Woydt, M. Tribological properties of thermal-sprayed Magnéli-type coatings with different stoichiometries $\left(\mathrm{Ti}_{\mathrm{n}} \mathrm{O}_{2 \mathrm{n}-1}\right)$. Surf. Coat. Technol. 2001, 140, 76-81. [CrossRef]

8. Heo, S.J.; Kim, K.H.; Kang, M.C.; Suh, J.H.; Park, C.G. Syntheses and mechanical properties of Mo-Si-N coatings by a hybrid coating system. Surf. Coat. Technol. 2006, 201, 4180-4184. [CrossRef]

9. Suszko, T.; Gulbinski, W.; Jagielski, J. The role of surface oxidation in friction processes on molybdenum nitride thin films. Surf. Coat. Technol. 2005, 194, 319-324. [CrossRef]

10. Lyo, I.W.; Ahn, H.S.; Lim, D.S. Microstructure and tribological properties of plasma-sprayed chromium oxide-molybdenum oxide composite coatings. Surf. Coat. Technol. 2003, 163-164, 413-421. [CrossRef]

11. Gassner, G.; Mayrhofer, P.H.; Kutschej, K.; Mitterer, C.; Kathrein, M. A new low Friction concept for high temperatures: Lubricious oxide formation on sputtered VN coatings. Tribol. Lett. 2004, 17, 751-756. [CrossRef] 
12. Fateh, N.; Fontalvo, G.A.; Gassner, G.; Mitterer, C. Influence of high-temperature oxide formation on the tribological behaviour of TiN and VN coatings. Wear 2007, 262, 1152-1158. [CrossRef]

13. Franz, R.; Mitterer, C. Vanadium containing self-adaptive low-friction hard coatings for high-temperature applications: A review. Surf. Coat. Technol. 2013, 228, 1-13. [CrossRef]

14. Pappacena, K.E.; Singh, D.; Ajayi, O.O.; Routbort, J.L.; Erilymaz, O.L.; Demas, N.G.; Chen, G. Residual stresses, interfacial adhesion and tribological properties of MoN/Cu composite coatings. Wear 2012, 278, 62-70. [CrossRef]

15. Kim, J.N.; Park, S.; Kim, T.; Lee, J.J. Structure and mechanical properties of Mo-N/Cu films produced by inductively coupled plasma reactive sputtering. Thin Solid Films 2011, 519, 6876-6880. [CrossRef]

16. Alami, J.; Bolz, S.; Sarakinos, K. High power pulsed magnetron sputtering: Fundamentals and applications. J. Alloy Compd. 2009, 483, 530-534. [CrossRef]

17. Shi, Y.J.; Pan, F.S.; Bao, M.D.; Yang, Z.L.; Wang, L. Effect of $\mathrm{N}_{2}$ flow rate on structure and property of $\mathrm{ZrNbAlN}_{\mathrm{x}}$ multilayer films deposited by magnetron sputtering. J. Alloy Compd. 2013, 559, 196-202. [CrossRef]

18. Wang, X.; Wang, L.S.; Qi, Z.B.; Yue, G.H.; Chen, Y.Z.; Wang, Z.C.; Peng, D.L. Investigation on the structure and properties of $\mathrm{Al}_{\mathrm{x}} \mathrm{Cr}_{1-\mathrm{x}} \mathrm{N}$ coatings deposited by reactive magnetron co-sputtering. J. Alloy. Compd. 2010, 502, 243-249. [CrossRef]

19. Lin, J.; Wu, Z.L.; Zhang, X.H.; Mishra, B.; Moore, J.J.; Sproul, W.D. A comparative study of $\mathrm{CrN}_{\mathrm{x}}$ coatings Synthesized by dc and pulsed dc magnetron sputtering. Thin Solid Films 2009, 517, 1887-1894. [CrossRef]

20. Mei, H.J.; Zhao, S.S.; Wu, Z.T.; Dai, W.; Wang, Q.M. Effect of nitrogen partial pressure on microstructure and mechanical properties of Mo-Cu-V-N composite coatings deposited by HIPIMS. Surf. Coat. Technol. 2017, 329, 68-76. [CrossRef]

21. Shin, J.H.; Wang, Q.M.; Kim, K.H. Microstructural evolution and tribological behavior of Mo-Cu-N coatings as a function of Cu content. Mater. Chem. Phys. 2011, 130, 870-879. [CrossRef]

22. Gulbiński, W.; Suszko, T.; Sienicki, W.; Warcholiński, B. Tribological properties of silver-and copper-doped transition metal oxide coatings. Wear 2003, 254, 129-135. [CrossRef]

23. Stoney, G.G. The tension of metallic films deposited by electrolysis. Proc. R. Soc. Lond. A Mater. 1909, 82, 172-175. [CrossRef]

24. Christie, D.J. Target material pathways model for high power pulsed magnetron sputtering. J. Vac. Sci. Technol. A 2005, 23, 330-335. [CrossRef]

25. Pelleg, J.; Zevin, L.Z.; Lungo, S. Reactive-sputter-deposited TiN films on glass substrates. Thin Solid Films 1991, 197, 117-128. [CrossRef]

26. Ihara, H.; Kimura, Y.; Senzaki, K.; Kezuka, H.; Hirabayashi, M. Electronic structures of B1 MoN, fcc Mo/sub 2/N, and hexagonal MoN. Phys. Rev. B 1985, 31, 3177-3178. [CrossRef]

27. Kim, G.T.; Park, T.K.; Chung, H.; Kim, Y.T.; Kwon, M.H.; Choi, J.G. Growth and characterization of chloronitroaniline crystals for optical parametric oscillators: I. XPS study of Mo-based compounds. Appl. Surf. Sci. 1999, 152, 35-43. [CrossRef]

28. Wang, T.; Zhang, G.J.; Ren, S.; Jiang, B.L. Effect of nitrogen flow rate on structure and properties of $\mathrm{MoN}_{\mathrm{x}}$ coatings deposited by facing target sputtering. J. Alloy. Compd. 2017, 701, 1-8. [CrossRef]

29. Lin, M.C.; Chang, L.-S.; Lin, H.C. Effects of nitrogen partial pressure on titanium oxynitride films deposited by reactive RF magnetron sputtering onto PET substrates. Surf. Coat. Technol. 2008, 202, 5440-5443. [CrossRef]

30. Hones, P.; Martin, N.; Regula, M.; Lévy, F. Structural and mechanical properties of chromium nitride, molybdenum nitride, and tungsten nitride thin films. J. Phys. D Appl. Phys. 2003, 36, 1023-1029. [CrossRef]

31. Zeman, P.; Cerstvý, R.; Mayrhofer, P.H.; Mitterter, C.; Musil, J. Structure and properties of hard and superhard Zr-Cu-N nanocomposite coatings. Mater. Sci. Eng. A 2000, 289, 189-197. [CrossRef]

32. Wan, X.S.; Zhao, S.S.; Yang, Y.; Gong, J.; Sun, C. Effects of nitrogen pressure and pulse bias voltage on the properties of Cr-N coatings deposited by arc ion plating. Surf. Coat. Technol. 2010, 204, 1800-1810. [CrossRef]

33. Luo, Q. Origin of friction in running-in sliding wear of nitride coatings. Tribol. Lett. 2010, 37, 529-539. [CrossRef]

34. Staia, M.H.; Pérez-Delgado, Y.; Sanchez, C.; Castro, A.; Bourhis, E.L.; Puchi-Cabrera, E.S. Hardness properties and high-temperature wear behaviour of nitrided AISI D2 tool steel, prior and after PAPVD coating. Wear 2009, 267, 1452-1461. [CrossRef] 
35. Luo, Q. Temperature dependent friction and wear of magnetron sputtered coating TiAlN/VN. Wear 2011, 271, 2058-2066. [CrossRef]

36. Gassner, G.; Mayrhofer, P.H.; Kutschej, K.; Mitterer, C.; Kathrein, M. Magnéli phase formation of PVD Mo-N and W-N coatings. Surf. Coat. Technol. 2006, 201, 3335-3341. [CrossRef]

37. Öztürk, A.; Ezirmik, K.V.; Kazmanlı, K.; Ürgen, M.; Eryılmaz, O.L.; Erdemir, A. Comparative tribological behaviors of TiN-, CrN- and MoN-Cu nanocomposite coatings. Tribol. Int. 2008, 41, 49-59. [CrossRef]

38. Dai, W.; Wang, A.Y. Deposition and properties of Al-containing diamond-like carbon films by a hybrid ion beam sources. J. Alloy. Compd. 2011, 509, 4626-4631. [CrossRef]

39. Muratore, C.; Voevodin, A.A. Chameleon Coatings: Adaptive surfaces to reduce friction and wear in extreme environments. Annu. Rev. Mater. Res. 2009, 39, 297-324. [CrossRef]

(C) 2018 by the authors. Licensee MDPI, Basel, Switzerland. This article is an open access article distributed under the terms and conditions of the Creative Commons Attribution (CC BY) license (http:/ / creativecommons.org/licenses/by/4.0/). 